\title{
Variation of Total Electron Content [TEC] and Their Effect on GNSS over Akure, Nigeria
}

\author{
Rufus Sola Fayose $^{1}$, Rabiu Babatunde ${ }^{2}$, Olakunle Oladosu ${ }^{3} \&$ Keith Groves $^{4}$ \\ ${ }^{1}$ Space Physics Laboratory Adekunle Ajasin University, Akungba Akoko, Nigeria \\ ${ }^{2}$ National Space Research \& Development Agency, NASRDA, Abuja, Nigeria \\ ${ }^{3}$ African Regional Center for Space Science and Technology Education in English (ARCSSTE-E), ILE-IFE, \\ Nigeria \\ ${ }^{4}$ Space Weather Center of Excellence, AFRL/VSBXI, USA \\ Correspondence: Rufus Sola Fayose, Space Physics Laboratory Adekunle Ajasin University, Akungba Akoko, \\ Nigeria. E-mail: sola.fayose@gmail.com.
}

Received: November 11, 2011

doi:10.5539/apr.v4n2p105

\author{
Accepted: December 2, 2011 Online Published: May 1, 2012 \\ URL: http://dx.doi.org/10.5539/apr.v4n2p105
}

\begin{abstract}
The effect of Space weather is usually linked to disturbances in the ionosphere (gradients in the Total electron content (TEC)). This has significant effect especially for GPS users causing degradation in range measurements, loss of lock by the receiver of the GPS signal. Knowledge of these TEC gradients is important to various GPS users. When a GPS signal encounters large gradients in TEC, the ionospheric error in the range measurement is difficult to model and therefore eliminated (for single frequency GPS users) or, in the case of differential GPS, cannot be canceled out. For differential GPS (DGPS) or real time kinematic (RTK) users, differences over the baseline as small as 2 TEC units, where one TEC unit is $10^{16}$ electrons $/ \mathrm{m}^{2}$, can be problematic in resolving ambiguities. Though quite a lot has been done in the developed nations in this respect, there is a dearth of such information for the developing region. This paper therefore presents the variation of total electron content (TEC) over a tropical in at Akure, Nigeria $\left(7.15^{\circ} \mathrm{N}, 5.12^{\circ} \mathrm{E}\right)$ using GPS data collected over a period of one year. The data was analyzed using the GPS-TEC analysis application software provided by Institute of scientific research, Boston College, USA. Result obtained shows significant daily and seasonal variation TEC gradients in the region.
\end{abstract}

Keywords: total electron content, GNSS, Akure, Nigeria

\section{Introduction}

The ionosphere is the ionized component of the atmosphere comprising free electrons and positive ions, generally in equal numbers, in a medium that is electrically neutral (Hunsucker and Hargreaves, 1995; Baumjohann, 1999). It plays a basic role in long-distance communication.

Characterizing the ionosphere is of utmost interest due to the numerous complexities associated with the region (Rabiu et al., 2007). Man's interest in the ionosphere developed largely because of ionospheric communications (Rama Rao et al., 1997), the improvement of which depends upon the increased knowledge of behaviour of the ionosphere. Since the ionosphere varies from place to place and from time to time, in other words the ionosphere exhibits both temporal and spatial variations hence it is important to study it at as many places as possible and for as long as possible.

The dispersive ionosphere introduces a time delay in the $1.57542 \mathrm{GHz}(\mathrm{L} 1)$ and $1.22760 \mathrm{GHz}$ (L2) simultaneous transmissions from GPS satellites orbiting at $20,200 \mathrm{~km}$. The relative ionospheric delay of the two signals is proportional to the total amount of electrons along the ray path, i.e., the total electron content (TEC). Time delay measurements of L1 and L2 frequencies can, therefore, be converted to TEC along the ray path from the receiver to the satellite (Lanyi \& Roth, 1988). The total electron content (TEC) provides an overall description of the ionization in the ionosphere, and it is also one of the most important ionospheric quantities for various practical applications. It is defined as the number of free electrons in a column of $1 \mathrm{~m}^{2}$ cross section extending from the ground to the top of the ionosphere, it is a parameter of great importance for systems which use trans-ionospheric radio waves. When a radio wave traverses the ionosphere, several effects are produced in it. Most of these effects are proportional, at least to the first order, to the TEC. The highest TEC values in the world occur at the 
equatorial anomaly (EA) peaks located at approximately $15^{\circ}$ either side of the magnetic equator (Ezquer et al., 2004).

The total electron content (TEC) is one of the most important parameters that describe the ionospheric state and structure. Theoretically, different periods of ionospheric physical process can be studied by detecting and analyzing the temporal variations of TEC. TEC can be used to correct the radio wave propagation in the space-based radio communication application like satellite position, navigation and orbit determination, because TEC is closely associated with the time delay of the radio wave which pierces the ionosphere. TEC has been measured for decades using the Faraday rotation effect on a linear polarized propagating plane wave. But today TEC measurements are made mostly using GPS data because of the good global coverage of the GPS observation network (Shim, 2009).

The Total Electron Content (TEC) can be estimated by using dual frequency GPS observations, an important parameter for characterizing the ionosphere and driving data assimilative models.

The Slant Total Electron Content (STEC) is the measure of the total number of free electrons in a column of the unit cross section along the path of the electromagnetic wave between the satellite and the receiver. The total number of free electrons is proportional to the ionospheric differential delay between L1 (1575.42 MHz) and L2 (1227.60 MHz) signals given by Mala S. Bagiya et al., 2009.

$$
\text { STEC }=\int_{\text {receiver }}^{\text {satellite }} N d s
$$

where $\mathrm{N}$ is the electron density; 1 TEC Unit $=10^{16}$ electrons $/ \mathrm{m}^{2}$.

The STEC is obtained from the dual frequency code measurements using the relation (Mala S. Bagiya et al., 2009):

$$
S T E C=\frac{1}{40.3} \times\left(\frac{1}{L_{1}^{2}}-\frac{1}{L_{2}^{2}}\right)^{-1} \times(P 1-P 2)+T E C_{C A L}
$$

where $\mathrm{P} 1$ is the Pseudo range at L1; P2 is the Pseudo range at $\mathrm{L} 2, \mathrm{TEC}_{\mathrm{cal}}$ is the bias error correction. STEC measured by the receiver at every $60 \mathrm{~s}$ was used. The measured STEC is corrected for the receiver differential delay $\mathrm{TEC}_{\mathrm{CAL}}$. The slant $\mathrm{TEC}$ is dependent on the ray path geometry through the ionosphere, an equivalent vertical value of TEC which is independent of the elevation of the ray path is calculated (Mala S. Bagiya et al., 2009). The Vertical TEC was obtained by taking the projection from the slant to vertical using the thin shell model assuming a height of $350 \mathrm{~km}$, following the technique given by Klobuchar (1986):

$$
\text { VTEC }=\text { STEC } \times \cos \left[\sin ^{-1}\left(\frac{R_{e} \cos \theta}{R_{e}+h_{\max }}\right)\right]
$$

where $\mathrm{R}_{\mathrm{e}}=6378 \mathrm{~km}, \mathrm{~h}_{\max }=350 \mathrm{~km}, \theta=$ elevation angle at the ground station.

Rama Rao et al. (2006) observed that the IPP (Ionospheric Pierce Point) altitude of $350 \mathrm{~km}$ is valid for the satellite elevation angle greater than $50^{\circ}$.

\section{Data Used}

The data used for this study were collected at the Space Physics Research laboratory of the Department of Physics, Federal University of Technology, Akure Nigeria by using NovAtel GSV 4004 GPS-SCINDA receiver. The GPS-SCINDA receiver tracks up to 14 GPS satellite signals simultaneously at the L1 frequency (1575.42 $\mathrm{MHz}$ ) and the L2 frequency (1227.6 MHz). It measures phase and amplitude (at 50-Hz rate) and code/carrier divergence (at 1-Hz) for each satellite tracked on L1 and then Slant Total Electron Content (STEC) are computed from the combined L1 and L2 pseudorange and carrier phase measurements for all the visible. The Signals were sampled at $50 \mathrm{~Hz}$ and $1 \mathrm{~Hz}$ and recorded every minute (60seconds interval).

All records from satellites below 15 degree were excluded as a first attempt at mitigating the effects of multipath. The remaining observations presented two irregularities. The first, and easiest to reconcile, was STEC and VTEC values of -999 that appeared periodically. This was identified as "bad data" in the original record. (Ron Caton, 2007) ascribes the -999 to extreme levels of scintillation when the elevation of the particular satellite was less than zero. A program was developed to perform data sorting and analysis for the study.

\section{Result \& Discussion}

Diurnal variations of vertical total electron content (VTEC) have been studied by plotting the monthly mean of TEC for January, March, August and October 2010 as shown in figures 1 to 4 respectively. The diurnal pattern 
of VTEC exhibited a steady increase from about sunrise to an afternoon maximum and then falls to attain a minimum just before sunrise. The diurnal variation in vertical total electron content (VTEC) at Akure, Nigeria show many characteristics typical of low latitude ionosphere such as a vertical total electron content (VTEC) minimum at pre-dawn and gradual increase with the time of the day attaining a maximum in the afternoon and a gradual decrease after sunset (Bagiya et. al., 2009; Aarons et. al., 1994). The daily peak valve of the VTEC occurs around 14:00 universal time. These curves show appreciable day-to-day variations of TEC, particularly, during the mid-day to pre-dawn hours which is a serious concern in forecasting and navigation (Bagiya et al., 2009; Rama Rao et al., 2006). The day-to-day variations of TEC may be attributed to the changes in solar activity which is associated with changes in the intensity of the incoming radiations (Kane, 1980; Mendillo et al., 1980; Modi \& Lyer, 1989). The diurnal variation in TEC shows that the time at which TEC attains maximum vary from day to day. Large variations of TEC are observed in daytime while nighttime variations are found to be almost constant.

The Seasonal variation of TEC is shown in Figure 5. TEC maximizes during September Equinox and minimizes during the D season in the January with intermediate values during summer months of March and June showing a semi-annual variation. The semi-annual variation of TEC was asymmetry with maximum in September Equinox.

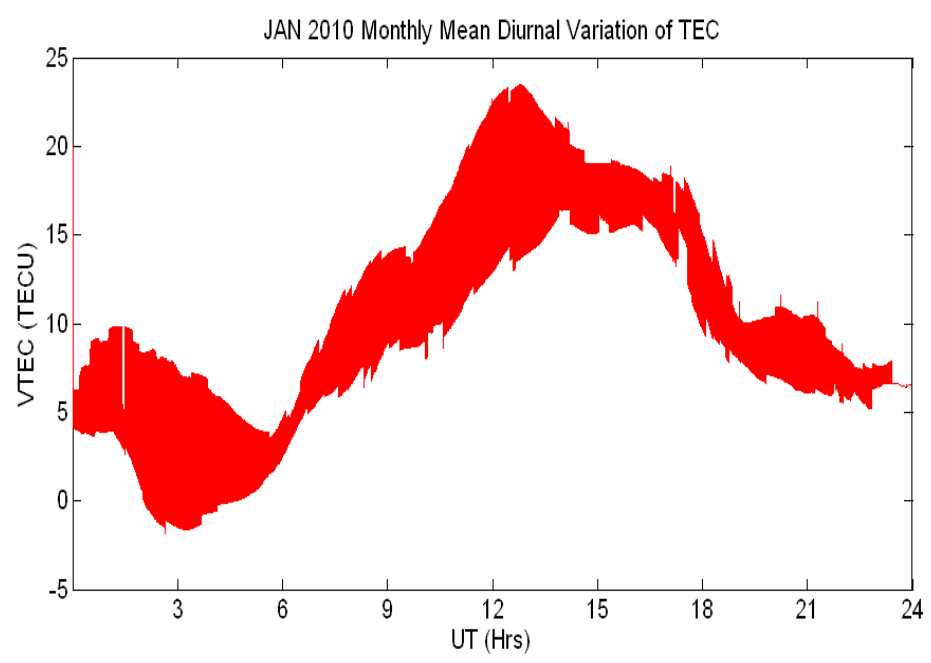

Figure 1. Monthly mean for Diurnal Variation of TEC observed for January 2010 from observing station, Akure $\left(7.15^{\circ} \mathrm{N}, 5.12^{\circ} \mathrm{E}\right)$

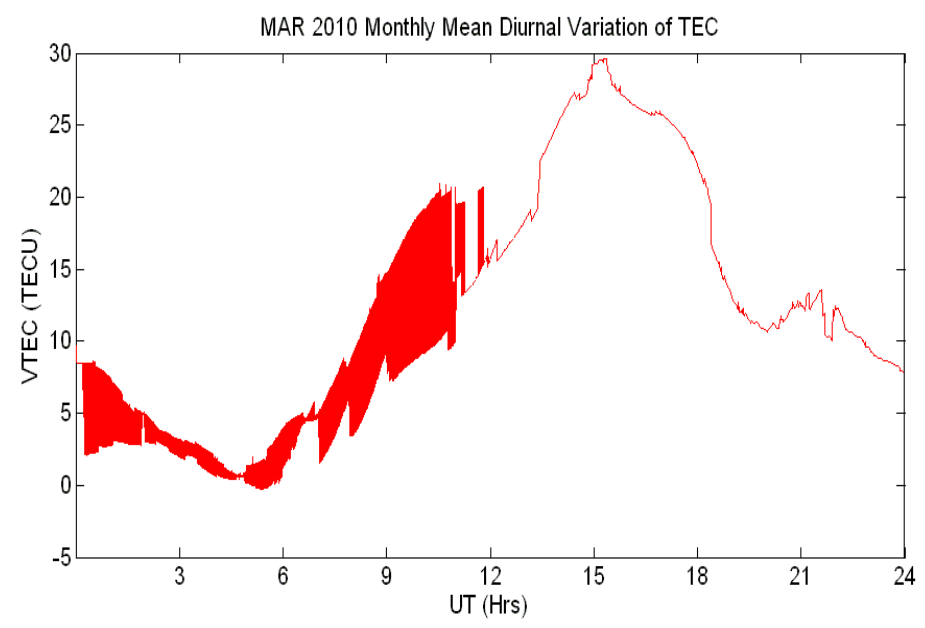

Figure 2. Monthly mean for Diurnal Variation of TEC observed for March 2010 from observing station, Akure $\left(7.15^{\circ} \mathrm{N}, 5.12^{\circ} \mathrm{E}\right)$ 


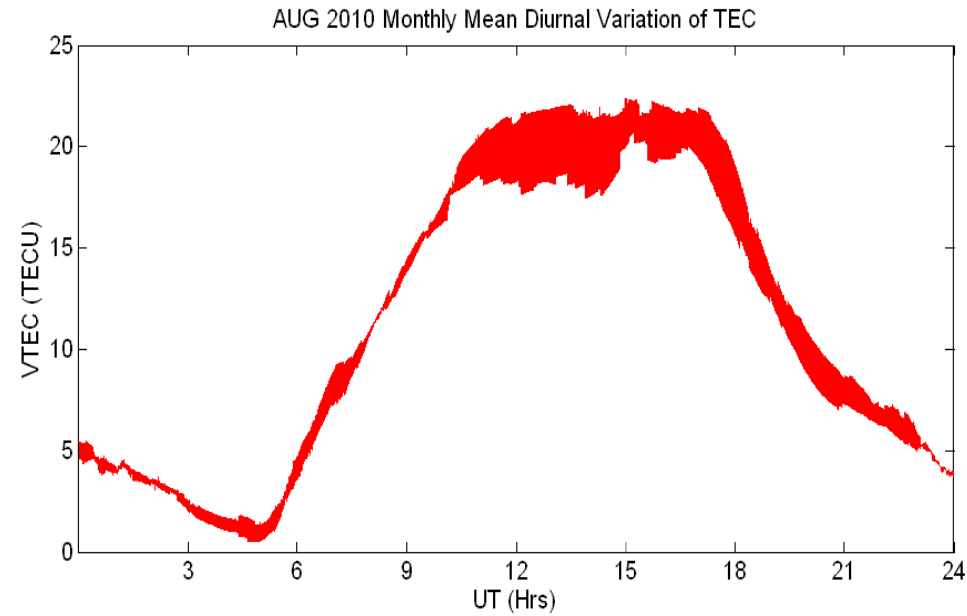

Figure 3. Monthly mean for Diurnal Variation of TEC observed for August 2010 from observing station Akure $\left(7.15^{\circ} \mathrm{N}, 5.12^{\circ} \mathrm{E}\right)$

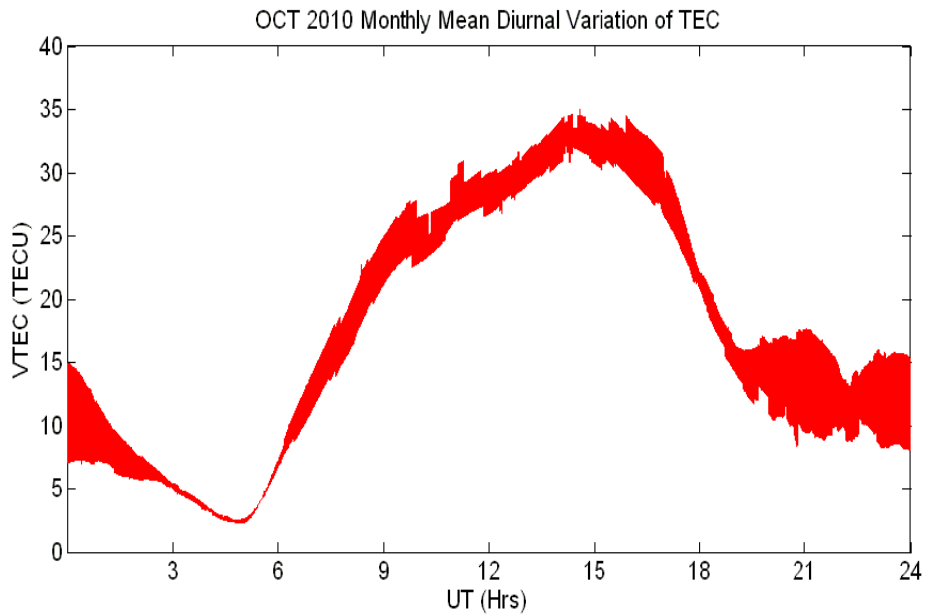

Figure 4. Monthly mean for Diurnal Variation of TEC observed for October 2010 from observing station, Akure $\left(7.15^{\circ} \mathrm{N}, 5.12^{\circ} \mathrm{E}\right)$

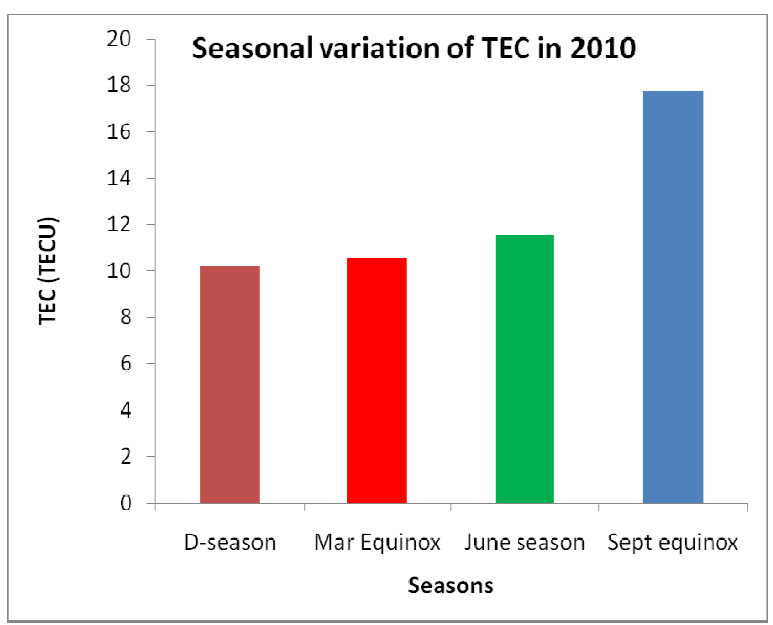

Figure 5. Seasonal Variation of TEC observed for 2010 from observing station Akure $\left(7.15^{\circ} \mathrm{N}, 5.12^{\circ} \mathrm{E}\right)$ 


\section{Conclusion}

The study of diurnal and seasonal dependence of TEC data has been carried out. The results showed that the mean TEC varies from a pre-dawn minimum to a maximum during the afternoon and then decreases. The low values of TEC are observed in winter and high values observed in equinox.

\section{References}

Bagiya, S. Mala, Joshi, H. P., Iyer, K. N., Aggarwal, M., Ravindran, S., \& Pathan, B. M. (2009). TEC variations during low solar activity period (2005-2007) near the Equatorial Ionospheric Anomaly Crest Region in India. Annales Geophysicae, 27, pp.1047-1057. http://dx.doi.org/10.5194/angeo-27-1047-2009

Dasgupta, A., \& Basu, A. (1973). Investigation of ionospheric electron content in the equatorial region as obtained by orbiting beacon satellites, Ann. Geophys., 29, 409-419.

Ezquer, R. G., Brunini, C., Mosert, M., Meza, A., Oviedo R. De, V., Kiorcheff, E., \& Radicella. (2004). GPS-VTEC measurements and IRI predictions in the South American sector. Advances in Space Research, 34, pp.2035-2043. http://dx.doi.org/10.1016/j.asr.2004.03.015

Hunsucker, R. D., \& Hargreaves, J. K. (1995). The high latitude Ionosphere and its effect on Radio propagation. Cambridge University Press.

Jamal, H., \& Gul, H. (2007). High precision antenna design with hybrid feeds for GPS requirements. In WSEAS International Conference on Applied Electromagnetics and Communications, ELECTROSCIENCE '07. Canary Islands, Spain.

Kane, R. P. (1980). Irregular variations in the global distribution of total electron content. Radio Sci., 15, pp. 837-842. http://dx.doi.org/10.1029/RS015i004p00837

Keith, Grooves, \& Charles, Carrano. (2009). Scintillation Impacts on GPS Workshop for Sustainable Development in Navigation Studies and Technology in Africa, lecture delivered at Abdus Salam. International Centre for Theoretical Physics (ICTP). Trieste, Italy, March 23-April 9.

Kelly, M. C. (1989). The Earth's Ionosphere; Plasma Physics and Electrodynamics. International Geophysics Series, Academic Press Inc., 43.

Kelley, M. C. (1989). The Earth's Ionosphere, International Geophysics Series. Academic Press, Inc.

Mannucci, A., Wilson, B., Yuan, D., Ho, C., Lindqwister, U., \& Runge, T. (1998). A global mapping technique for GPS derived ionospheric total electron content measurements. Radio Sci., 33(3), 565-582. http://dx.doi.org/10.1029/97RS02707

Mendillo, M., Lynch, F. X., \& Klobuchar, J. A. (1980). Solar Terrestrial Predictions, vol. 4. edited by: Donneylly, R. F., Space Environment Lab, Boulder, Colorado, USA, C1-C14.

Modi, R. P., \& Iyer, K. N. (1989). IEC and slab thickness near the peak of equatorial anomaly during sunspot maximum and minimum. Indian Journal of Radio and Space Physics, 18, 23-26.

Rabiu, A. B., Mamukuyomi, A. I., \& Joshua, E. O. (2007). Variability of equatorial ionosphere inferred from geomagnetic field measurement. Bulletin astronomy society India, 1-12.

Rama Rao, P.V.S., Gopi Krishna, S., Niranjan, K., \& Prasad, S. V. V. D. (2006). Temporal and spatial variations in TEC using simultaneous measurements from the Indian network of receivers during the low solar activity period of 2004-2005. Annales Geophysicae, 24, 3279-3292. http://dx.doi.org/10.5194/angeo-24-3279-2006

Rastogi, R. G., \& Sharma, R. P. (1971). Ionospheric electron content at Ahmedabad (near the crest of equatorial anomaly) by using beacon satellite transmissions during half a solar cycle, Planet. Space Sci., 19, 1505-1517, 1971. http://dx.doi.org/10.1016/0032-0633(71)90010-9 